\title{
Substituição da farinha de carne suína por fontes vegetais em dietas para carpa-húngara
}

\author{
Giovani Taffarel Bergamin(1), João Radünz Neto(1), Tatiana Emanuelli(1), \\ Rafael Lazzari(2), Daniel Maschio ${ }^{(1)}$ e Vanessa Knapp ${ }^{(1)}$
}

(1)Universidade Federal de Santa Maria (UFSM), Avenida Roraima, № 1.000, Cidade Universitária, Bairro Camobi, CEP 97105-900 Santa Maria, RS. E-mail: giovanitb@gmail.com, jradunzneto@yahoo.com.br, etaty@terra.com.br, dani.maschio@hotmail.com, vanessappank@yahoo.com.br(2)UFSM, Centro de Educação Superior Norte, Avenida Independência, 3.751, CEP 98300-000 Palmeira das Missões, RS. E-mail: rafaellazzari@yahoo.com.br

Resumo - O objetivo deste trabalho foi avaliar o crescimento e a qualidade de carcaça de carpa-húngara alimentada com dietas em que houve substituição da farinha de carne suína por farelos de soja e canola, bem como determinar parâmetros bioquímicos do metabolismo dos peixes e a qualidade sensorial do filé. Cada um dos farelos contribuiu com $50 \%$ da proteína na mistura. Cinco dietas foram avaliadas, com níveis de substituição $(0,25,50,75$ e $100 \%)$ da proteína da farinha de carne suína pela mistura das fontes vegetais. A inclusão de fontes proteicas vegetais nas dietas reduziu o crescimento, a deposição de gordura corporal e no filé, e o colesterol total dos peixes. A cor e o sabor dos filés não foram afetados pela inclusão das fontes proteicas vegetais. A dieta à base de farinha de carne suína é mais eficiente para o crescimento da carpa-húngara, e proporciona maior deposição de proteína no peixe inteiro e no filé.

Termos para indexação: Cyprinus carpio, farelo de canola, farelo de soja, fonte proteica animal, proteína.

\section{Replacement of pork meal by plant protein sources in Hungarian carp diets}

\begin{abstract}
The objective of this work was to evaluate growth and carcass composition of Hungarian carp fed with diets in which pork meat meal was replaced by a combination of canola and soybean meals, as well as to determine fish metabolism biochemical parameters and the sensorial quality of the fillet. Each plant meal contributed with $50 \%$ of the dietary protein of the mixture. Five diets were tested, with replacement levels of 0 , $25,50,75$ and $100 \%$ of pork meal by plant protein sources. The inclusion of the plant-protein meal in the diet results in lower overall growth, lower body and fillet lipid deposition and lower total cholesterol of the fish. Color and flavor of the fillets were not affected by inclusion of plant protein sources. A pork meat meal based diet is more efficient for Hungarian carp growth, and provides higher whole fish and fillet protein deposition.
\end{abstract}

Index terms: Cyprinus carpio, canola meal, soybean meal, animal protein, protein.

\section{Introdução}

A piscicultura brasileira é a atividade de produção animal que mais cresce no país. Entre as espécies de peixes criadas no sul do Brasil destacam-se as carpas, em especial a carpa-húngara (Cyprinus carpio Linnaeus, 1758). Este peixe é utilizado em policultivo com outras carpas, como a carpa-capim (Ctenopharyngodon idella Valenciennes, 1844), a carpa-prateada (Hypophthalmichthys molitrix Valenciennes, 1844) e a carpa-cabeça-grande (Aristichthys nobilis Richardson, 1854), em sistemas de produção semi-intensivos, a baixo custo, com aproveitamento de resíduos agroindustriais em sua alimentação (Silva et al., 2006). Porém, o êxito na produção final depende do manejo alimentar empregado nas fases iniciais de cultivo (alevinagem e recria), em que se faz necessário o uso de dietas balanceadas que possibilitem o máximo aproveitamento de nutrientes.
A aquicultura demanda fontes de proteína de alta qualidade (Naylor et al., 2000). As fontes de origem animal ainda são a base para a formulação de dietas para peixes, por apresentarem alto nível de proteína, composição equilibrada em aminoácidos e pouco ou nenhum fator antinutricional (El-Sayed, 1999). Afarinhade carne éo principal subproduto de abatedouro utilizado na nutrição animal, e faz parte da composição básica de dietas comerciais para peixes como redutor de custos das formulações (Campestrini, 2005). Ela possui, em média, $50 \%$ de proteína bruta, $30 \%$ de matéria mineral e de 10 a $20 \%$ de gordura (Allan \& Rowland, 2005). Entretanto, a produção inconstante e a grande variabilidade de composição entre lotes produzidos podem comprometer a utilização da farinha de carne (Campestrini, 2005). Quando utilizada em dietas desequilibradas nutricionalmente, esse tipo de fonte de proteína contribui para maior excreção de nitrogênio e fósforo pelos peixes, o que é negativo do 
ponto de vista ambiental, além de aumentar a deposição de gordura na carcaça e vísceras (Jahan et al., 2003a, 2003b).

Os farelos de origem vegetal têm sido avaliados para inclusão em dietas aquícolas, pois possuem composição mais constante, porém com restrições de inclusão pela presença de compostos tóxicos ou inibidores de crescimento (Gatlin III et al., 2007). Como alternativa, tem-se utilizado a combinação de fontes vegetais de diferentes origens aliada à suplementação com aminoácidos livres dos aminoácidos limitantes, a fim de se obter dietas com qualidade proteica equivalente à obtida a partir das fontes de origem animal.

No Brasil, diversos farelos são produzidos em larga escala, como subprodutos da indústria de óleos. Entre eles, destacam-se os farelos de soja e canola, ricos em proteína e amplamente utilizados na alimentação animal (Müller et al., 2007).

O objetivo deste trabalho foi avaliar o crescimento e a qualidade de carcaça de carpa-húngara, alimentada com dietas em que houve substituição da farinha de carne suína por farelos de soja e canola, bem como determinar parâmetros bioquímicos do metabolismo dos peixes e a qualidade sensorial do filé.

\section{Material e Métodos}

O trabalho foi realizado no Laboratório de Piscicultura da Universidade Federal de Santa Maria $\left(29^{\circ} 43^{\prime} \mathrm{S}, 53^{\circ} 42^{\prime} \mathrm{W}\right.$, altitude $\left.95 \mathrm{~m}\right)$, entre os meses de fevereiro e abril de 2008. Para a realização do experimento, foi utilizado um sistema de recirculação de água com temperatura controlada, composto por 15 tanques de $280 \mathrm{~L}$ e filtros mecânico e biológico. A unidade experimental foi constituída por tanque de $280 \mathrm{~L}$ com nove juvenis.

Foram utilizados 135 peixes com peso inicial de $238,05 \pm 1,29 \mathrm{~g}$, provenientes de piscicultura comercial, obtidos através de desova induzida. Antes do início do experimento, os peixes foram selecionados por tamanho, passaram por período de adaptação nas unidades experimentais, e receberam ração comercial extrusada ( $32 \%$ de proteína bruta).

Utilizou-se o delineamento experimental inteiramente casualizado, com cinco tratamentos e três repetições. Cinco dietas compuseram os tratamentos, com substituição gradual $(0,25,50,75$ e $100 \%)$ da proteína da farinha de carne suína pela mistura dos farelos de soja e canola (Tabela 1). A proporção entre farelo de canola e de soja foi definida de forma que cada um contribuísse com $50 \%$ do teor proteico da mistura. Os ingredientes foram analisados para se obter os valores de composição centesimal e aminoácidos, para o ajuste das dietas de acordo com as exigências da espécie (National Research Council, 1993).

Para fornecimento aos animais, a ração foi triturada grosseiramente a fim de se obter grânulos adequados ao consumo, com tamanho entre 3 a $8 \mathrm{~mm}$, de acordo com o crescimento dos peixes. Os peixes foram alimentados duas vezes ao dia, com uma quantidade

Tabela 1. Composição das dietas para carpa-húngara (Cyprinus carpio) utilizadas no experimento.

\begin{tabular}{|c|c|c|c|c|c|}
\hline \multirow[t]{2}{*}{ Composição } & \multicolumn{5}{|c|}{ Níveis de substituição $(\%)^{(1)}$} \\
\hline & 0 & 25 & 50 & 75 & 100 \\
\hline \multicolumn{6}{|l|}{ Ingredientes (\% MS) } \\
\hline Farinha de carne suína & 52,00 & 39,00 & 26,00 & 13,00 & - \\
\hline Farelo de soja & - & 7,36 & 14,72 & 22,08 & 29,44 \\
\hline Farelo de canola & - & 7,86 & 15,72 & 23,58 & 31,44 \\
\hline Farelo de trigo & 35,99 & 33,77 & 30,35 & 30,23 & 27,31 \\
\hline Milho moído (grãos) & 5,00 & 5,00 & 6,00 & 4,00 & 2,60 \\
\hline Óleo de soja & 2,00 & 2,00 & 2,20 & 2,10 & 3,70 \\
\hline Mistura vitamínica ${ }^{(2)}$ & 2,00 & 2,00 & 2,00 & 2,00 & 2,00 \\
\hline Mistura mineral ${ }^{(3)}$ & 1,00 & 1,00 & 1,00 & 1,00 & 1,00 \\
\hline Fosfato bicálcico & 1,00 & 1,00 & 1,00 & 1,00 & 1,00 \\
\hline Cloreto de sódio & 1,00 & 1,00 & 1,00 & 1,00 & 1,00 \\
\hline BHT & 0,01 & 0,01 & 0,01 & 0,01 & 0,01 \\
\hline L-Lisina & 0,21 & 0,21 & 0,22 & 0,22 & 0,22 \\
\hline DL-Metionina & 0,41 & 0,42 & 0,42 & 0,44 & 0,45 \\
\hline L-Treonina & 0,17 & 0,15 & 0,12 & 0,10 & 0,07 \\
\hline Cálcio & 3,24 & 2,59 & 1,95 & 1,30 & 0,84 \\
\hline Fósforo & 1,98 & 1,70 & 1,40 & 1,14 & 0,84 \\
\hline \multicolumn{6}{|l|}{ Composição centesimal (\% MS) } \\
\hline Matéria seca & 95,16 & 94,28 & 94,05 & 91,96 & 91,94 \\
\hline Proteína bruta & 33,82 & 34,91 & 34,27 & 33,83 & 32,72 \\
\hline Extrato etéreo & 16,48 & 13,64 & 11,52 & 8,65 & 8,55 \\
\hline Matéria mineral & 15,40 & 13,71 & 12,37 & 10,31 & 8,70 \\
\hline Fibra em detergente neutro & 17,67 & 19,44 & 18,85 & 18,92 & 17,47 \\
\hline Extrativo não-nitrogenado & 11,78 & 13,00 & 17,04 & 20,25 & 24,50 \\
\hline Energia digestível $\left(\mathrm{kcal} \mathrm{kg}^{-1}\right)^{(4)}$ & 3.099 & 3.005 & 2.926 & 2.819 & 2.799 \\
\hline
\end{tabular}

${ }^{(1)}$ Substituição da farinha de carne suína pela mistura de farelo de soja + farelo de canola. ${ }^{(2)} \mathrm{Um}$ porcento de cloreto de colina $(50 \%)+1 \%$ de mistura vitamínica (MigPlus). Composição da mistura vitamínica por kg de produto: Ácido Fólico, $3.000 \mathrm{mg}$; Ácido Nicotínico, $60.000 \mathrm{mg}$; Ácido Pantotênico, $30.000 \mathrm{mg}$; Biotina, $100 \mathrm{mg}$; Vit.A, 10.000.000 UI; Vit. B1, $8.000 \mathrm{mg}$; Vit. B2, 10.000 mg; Vit. B6, 8.000 mg; Vit. B12, 20.000 mcg; Vit. C, 150.000 mg; Vit. D3, 2.000.000 UI; Vit. E, $150.000 \mathrm{mg}$; Vit. K3, $6.000 \mathrm{mg}$; Inositol, $88.000 \mathrm{mg} \cdot{ }^{(3)}$ Composição da mistura mineral por kg de produto MigPlus: Ferro, $30.000 \mathrm{mg}$; Manganês, $5.000 \mathrm{mg}$; Cobre, $2.000 \mathrm{mg}$; Zinco, $20.000 \mathrm{mg}$; Iodo; $900 \mathrm{mg}$; Cobalto, $20 \mathrm{mg}$; Selênio, $100 \mathrm{mg}$. ${ }^{(4)}$ Calculada: $\mathrm{ED}=\mathrm{PB} \times 5,64 \times 0,75+\mathrm{EE} \times 9,44 \times 0,9+\mathrm{ENN} \times 4,11 \times 0,75$, adaptado de Bureau et al. (2002). 
correspondente a $3 \%$ do peso vivo, às 9 e $15 \mathrm{~h}$. Uma hora após cada alimentação, realizou-se a limpeza dos tanques por sifonagem, para retirada das fezes e eventuais resíduos de ração. Para a coleta dos dados e ajuste da quantidade de ração fornecida, realizaramse biometrias a cada 18 dias. Antes de cada biometria, os peixes foram submetidos a jejum por 24 horas, tendo sido sedados em trifenoxietanol $(0,03 \%)$ para o procedimento. Em cada biometria foram medidos o comprimento total $(\mathrm{cm})$, comprimento padrão $(\mathrm{cm})$, peso $(\mathrm{g})$ e altura dorsal $(\mathrm{cm})$.

A partir dos dados obtidos, foram calculados: fator de condição, taxa de crescimento específico $\left(\%\right.$ dia $\left.^{-1}\right)$, $\mathrm{TCE}=[\ln ($ peso final) $-\ln ($ peso inicial) $] /$ dias $\times 100$; conversão alimentar aparente, CAA $=$ (consumo ração)/(biomassa final - biomassa inicial); ganho em peso médio diário $\left(\mathrm{g} \mathrm{dia}^{-1}\right)$ : GMD = (peso final - peso inicial)/dias; e ganho em peso relativo ( $\%$ do peso inicial $), \mathrm{GPR}=[($ peso final - peso inicial $) /$ peso inicial $]$ $\mathrm{x} 100$.

Ao final do experimento, os animais passaram por jejum de 24 horas, e três juvenis por unidade experimental foram abatidos por hipotermia em uma mistura de água e gelo 1:1. Após esse procedimento, os animais foram eviscerados e tiveram os filés retirados a fim de se calcular os valores de peso de carcaça, peso de filé, peso de trato digestivo, peso de fígado e comprimento de trato digestivo. Com base nesses valores foram calculados: rendimento de carcaça ( $\mathrm{RC}$, (peso carcaça/peso inteiro) x 100) e de filé (RF, (peso do filé/peso inteiro) x 100, em \%), índice hepatossomático (IHS, (peso do fígado/peso inteiro) x 100, em \%) e índice digestivo-somático (IDS, (peso do trato digestivo/peso inicial) x 100, em \%) e o quociente intestinal (QI, (comprimento do trato digestivo/comprimento total) x 100, em \%). A composição centesimal dos filés foi analisada de forma semelhante à realizada para o peixe inteiro, descrita a seguir.

Para a análise de composição centesimal do peixe inteiro, um peixe por unidade experimental foi abatido e triturado em multiprocessador de alimentos. A umidade foi determinada pela perda de peso após 48 horas a $60^{\circ} \mathrm{C}$ em estufa com circulação forçada de ar, seguida de 8 horas a $105^{\circ} \mathrm{C}$. O conteúdo de cinzas foi determinado pela queima a $550^{\circ} \mathrm{C}$ por quatro horas. A proteína bruta $(\mathrm{N} \times 6,25)$ foi determinada pelo método de Kjeldahl (micro) e a gordura foi extraída e quantificada de acordo com o método de Bligh \& Dyer (1959).

As análises de composição do filé e do peixe inteiro permitiram o cálculo das seguintes taxas:

$$
\begin{gathered}
\mathrm{CRP}=100 \times(\mathrm{Pf} \times \mathrm{PBCf}-\mathrm{Pi} \times \mathrm{PBCi}) / \mathrm{ACt} \times \mathrm{PBd} ; \\
\mathrm{DPC}=\mathrm{Pf} \times \mathrm{PBCf} / 100-\mathrm{Pi} \times \mathrm{PBCi} / 100 ; \\
\mathrm{DGC}=\mathrm{Pf} \times \mathrm{GCf} / 100-\mathrm{Pi} \times \mathrm{GCi} / 100 ; \\
\mathrm{DPF}=\mathrm{Pf} \times \mathrm{PBFf} / 100-\mathrm{Pi} \times \mathrm{PBFi} / 100 ; \\
\mathrm{DGF}=\mathrm{Pf} \times \mathrm{GFf} / 100-\mathrm{Pi} \times \mathrm{GFi} / 100,
\end{gathered}
$$

cujas siglas têm os seguintes significados: CRP, coeficiente de retenção protéica; DPC, deposição de proteína corporal; DGC, deposição de gordura corporal DPF, deposição de proteína no filé; DGF, deposição de gordura no filé; Pf e Pi, peso final e peso inicial dos animais; PBd, proteína bruta da dieta; Act, quantidade total de alimento consumido; $\mathrm{PBCi}$, proteína corporal inicial; PBCf, proteína corporal final; $\mathrm{PBC}$, proteína bruta da dieta; GCi, gordura corporal inicial; GCf, gordura corporal final; PBFi, proteína do filé inicial; PBFf, proteína do filé final; GFi, gordura do filé inicial; GFf, gordura do filé final.

A coleta de sangue foi realizada em dois peixes por unidade experimental. $\mathrm{O}$ sangue foi coletado na veia caudal, usando seringas heparinizadas. Cada amostra foi dividida em duas subamostras, uma para análise das aminotransferases e outra para as análises bioquímicas. As análises de aspartato aminotransferase e alanina aminotransferase foram realizadas em laboratório clínico especializado, com o uso de métodos enzimáticos e de diagnóstico ortoclínico, reagentes Johnson \& Johnson e analisador totalmente automatizado Vitros 950 (Dry Chemistry, Rochester, New York). Os demais parâmetros bioquímicos - glicose, colesterol, triglicerídeos e proteínas totais - foram analisados no plasma obtido das amostras centrifugadas (3.000 rpm por $10 \mathrm{~min}$ ), e foram mensurados com kits colorimétricos (Doles, Goiânia, Brasil).

No início e no final do experimento, foram realizadas análises da cor dos filés, avaliada por meio de um colorímetro Minolta CR-300 (Konica Minolta, Osaka, Japão), de acordo com as normas da Comissão Internacional de Iluminação (CIE 1976 L*a*b*), com sistema de iluminação padrão D65, com $10^{\circ}$ de ângulo de observação. Os parâmetros de cor avaliados foram luminosidade $\left(\mathrm{L}^{*}\right)$ e cromaticidade da amostra $\left(+\mathrm{a}^{*}\right.$ direção para o vermelho, -a* direção para o verde,

Pesq. agropec. bras., Brasília, v.45, n.10, p.1189-1197, out. 2010 
$+b^{*}$ direção para o amarelo e -b* direção para o azul). Cada amostra foi analisada três vezes, girando-se $90^{\circ}$ a amostra entre as leituras.

No final do experimento, foi realizada análise sensorial dos filés com painel não treinado. Para tal, os filés foram assados inteiros em forno elétrico convencional a $250^{\circ} \mathrm{C}$ por 20 minutos, imediatamente antes da análise sensorial. A aceitabilidade global foi avaliada utilizando-se o teste de preferência por ordenamento de acordo com a cor e o sabor das amostras (Meilgaard et al., 1991). Trinta painelistas não treinados receberam cinco amostras de filé (tratamentos 0, 25, 50, 75 e 100) em pequenas porções de $5 \mathrm{~g}$, aproximadamente, e foram instruídos a ordenar as amostras em ordem decrescente de aceitabilidade. Dessa forma, as amostras preferidas pelos painelistas receberam as pontuações mais baixas.

Os dados obtidos foram submetidos a teste de normalidade e a regressão polinomial a $5 \%$ de probabilidade. $\mathrm{Na}$ análise sensorial, o valor crítico para a obtenção de diferença significativa entre os tratamentos, em que se utiliza trinta painelistas e cinco amostras em nível de $5 \%$ de significância, é 34, de acordo com a Tabela de Newell \& Mc Farlane (Dutcosky, 2007).

\section{Resultados e Discussão}

Os parâmetros de qualidade da água se mantiveram dentro dos limites aceitáveis para a espécie (Poli \& Arana, 2004; Zaniboni Filho, 2004). Os valores de temperatura $\left({ }^{\circ} \mathrm{C}\right)$, oxigênio dissolvido $\left(\mathrm{mg} \mathrm{L}^{-1}\right), \mathrm{pH}$, alcalinidade ( $\left.\mathrm{mg} \mathrm{L}^{-1}\right)$, amônia $\left(\mathrm{mg} \mathrm{L}^{-1}\right)$ e nitrito $\left(\mathrm{mg} \mathrm{L}^{-1}\right)$ foram $23,0 \pm 2,3 ; 4,9 \pm 1,1 ; 6,4 \pm 0,2 ; 25,5 \pm 9,2 ; 0,4 \pm 0,1 \mathrm{e}$ $0,1 \pm 0,01$, respectivamente.

Ao final do experimento ( 72 dias), o peso final, a taxa de crescimento específico e o ganho em peso relativo apresentaram efeito linear negativo da substituição de farinha de carne pela mistura de farelos vegetais (Figura 1). Além disso, observou-se decréscimo da conversão alimentar aparente conforme aumentou-se a inclusão de farelos vegetais na dieta.

Muitos trabalhos têm sido feitos com vistas à substituição de fontes de origem animal por fontes vegetais, com resultados que variam de acordo com as fontes e as espécies de peixe utilizadas. Para larvas de tilápia-do-nilo(Oreochromis niloticus Linnaeus, 1758), os farelos de soja, girassol e canola podem suprir $50 \%$ da proteína exigida pela espécie, completada pela inclusão de farinha de peixe (Souza et al., 2004). Jahan et al. (2003a), ao avaliar o desempenho e a excreção de fósforo e nitrogênio pela carpa-comum (Cyprinus carpio Linnaeus, 1758), verificaram que o uso de diversos ingredientes - farinha de penas, farinha de carne ou concentrado proteico de soja - na mesma dieta promoveu melhor balanço de aminoácidos, apesar dos baixos níveis de farinha de peixe (15\% na dieta). No mesmo trabalho, a taxa de eficiência proteica não apresentou diferença entre as dietas, porém o tratamento com farinha de carne resultou em maior peso final e ganho de peso, enquanto os demais tratamentos proporcionaram desempenho similar entre si. Por sua vez, Goda et al. (2007) substituíram a farinha de peixe por farinha de vísceras de aves, farinha de carne e ossos ou farelo de soja em dietas para bagre-africano (Clarias gariepinus Burchell, 1822). Os autores verificaram que o farelo de soja pode substituir totalmente a farinha de peixe da dieta, sem comprometer o crescimento dos animais. Kim et al. (1997) substituíram a proteína proveniente da farinha de peixe por farelo de soja e soja integral tostada para juvenis de Cyprinus carpio. Os autores relatam que o farelo de soja pode substituir até $75 \%$ da proteína proveniente da farinha de peixe da dieta sem prejuízo para o desempenho. Quanto à soja integral tostada, o nível máximo de substituição foi de $50 \%$.

Mesmo na associação do farelo de soja com farelo de canola, preparada de forma a diluir a concentração de fatores antinutricionais da soja, observou-se que a substituição da proteína da farinha de carne pelos farelos vegetais levou a menores índices de desempenho. $\mathrm{O}$ efeito deletério da inclusão de fontes vegetais sobre o crescimento dos animais pode estar relacionado à presença de fibra, fatores antinutricionais (remanescentes) e baixa palatabilidade, que podem diminuir a ingestão de alimento pelos peixes (Luo et al., 2006).

Embora o perfil de aminoácidos das dietas tenha sido similar, as diferenças encontradas podem ter sido resultantes da diferente disponibilidade de aminoácidos entre os tratamentos. Segundo Hasan et al. (1997), durante o processamento dos subprodutos vegetais, a lisina pode reagir com moléculas não proteicas presentes nos próprios ingredientes, e formar compostos que tornam este aminoácido indisponível, mas quimicamente mensurável. 
Em trabalho com tilápia-do-nilo, Pereira-da-Silva \& Pezzato (2000) testaram a palatabilidade de alguns ingredientes utilizados na alimentação de peixes e os classificaram em três grupos: 1) baixa atratopalatabilidade: farelos de trigo, soja e algodão, farinha e raspa de mandioca, farinha de girassol e fubá de milho; 2) média atrato-palatabilidade, levedura de cana-de-açúcar e glúten de milho; 3) alta atrato-palatabilidade, ovo integral liofilizado, farinhas de crisálidas, peixe, carne e camarão. Portanto, além da questão nutricional, outro fator que pode ter influenciado os resultados deste trabalho é a palatabilidade das dietas. Os autores citados não avaliaram o farelo de canola, mas informações da literatura indicam que o farelo de canola é mais palatável que o farelo de soja (Viegas et al., 2008). O desempenho superior da dieta controle em ambos os experimentos pode estar relacionado à alta palatabilidade inerente aos ingredientes de origem animal e consequente maior consumo de ração, apesar de a taxa de ingestão de alimento pelos peixes não ter sido avaliada e de os peixes terem recebido quantidade fixa de ração diariamente.

A composição centesimal do peixe inteiro e do filé - umidade, cinzas, gordura e proteína - não foi afetada pelos tratamentos (Tabelas 2 e 3). Já as deposições de proteína e gordura no filé (DPF e DGF) e de gordura corporal(DGC) tiveram efeito linear negativo, enquanto a deposição de proteína corporal não apresentou efeito significativo.

Jahan et al. (2003b), com a utilização de farinha de penas, farinha de carne ou farelo de soja na alimentação de carpa-húngara, não encontraram
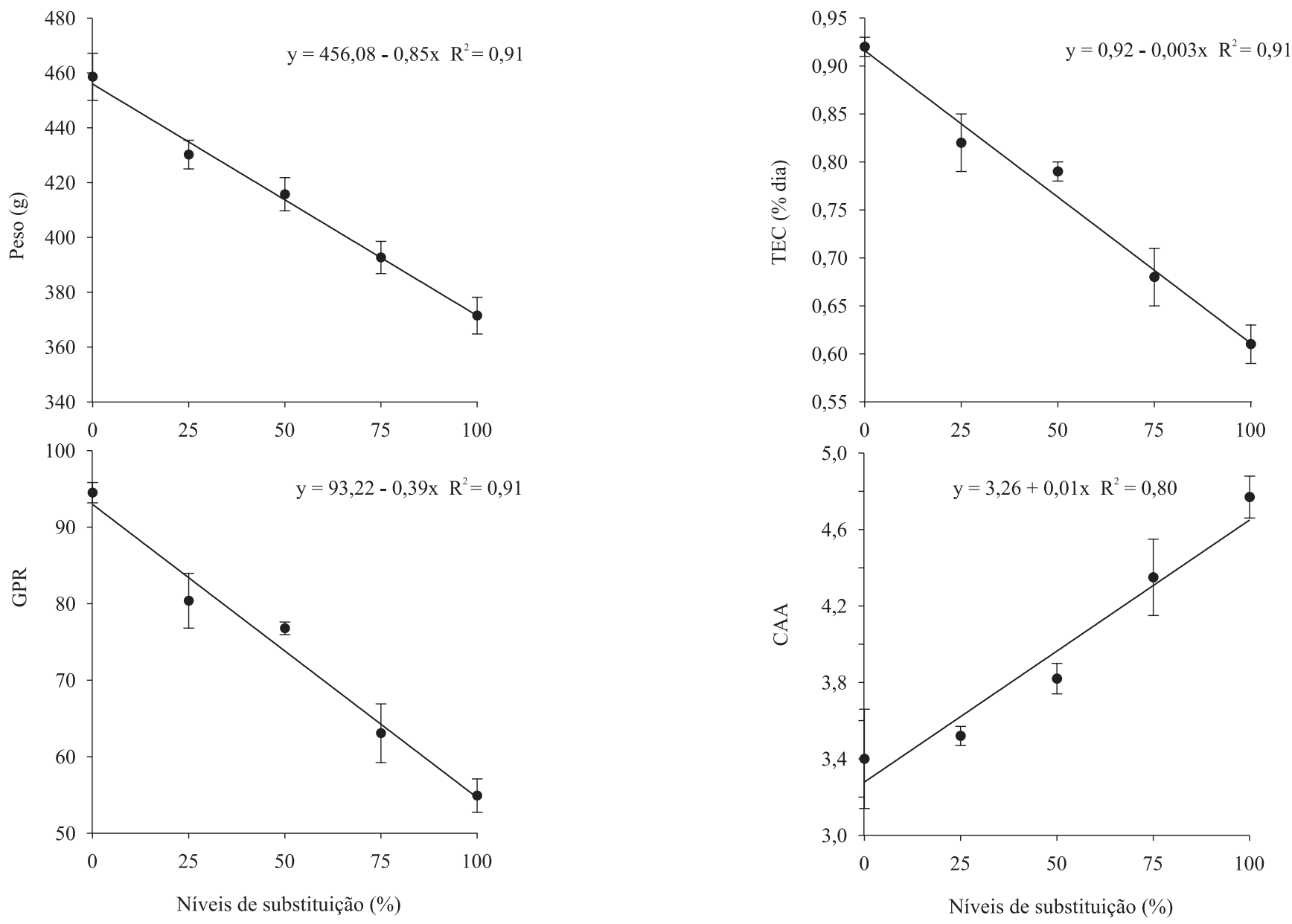

Figura 1. Desempenho dos juvenis de carpa húngara (Cyprinus carpio) alimentados com dietas contendo níveis de substituição da farinha de carne suína por farelo de soja + farelo de canola. TCE: taxa de crescimento específico; GPR: ganho em peso relativo; CAA: conversão alimentar aparente. 
diferenças na composição do peixe inteiro, e os valores observados por eles foram semelhantes aos deste trabalho. Os dados de gordura no peixe inteiro $(12,03$ a $15,45 \%$ ) foram maiores que os encontrados por Kim et al. (1997) (10,07 a 11,80\%). Esses autores utilizaram animais com peso médio semelhante ao deste trabalho e, quando substituíram a farinha de peixe por $50 \mathrm{ou}$ $75 \%$ de farelo de soja, não encontraram diferenças

Tabela 2. Composição centesimal do peixe inteiro e do filé dos juvenis de carpa húngara (Cyprinus carpio).

\begin{tabular}{|c|c|c|c|c|c|c|c|}
\hline \multirow[t]{2}{*}{ Variáveis } & \multicolumn{5}{|c|}{ Tratamentos $^{(1)}$} & \multirow[t]{2}{*}{$\mathrm{CV}(\%)$} & \multirow[t]{2}{*}{ Efeito } \\
\hline & 0 & 25 & 50 & 75 & 100 & & \\
\hline & \multicolumn{7}{|c|}{ Peixe inteiro } \\
\hline Umidade (\%) & 65,09 & 65,44 & 64,72 & 67,81 & 68,03 & 4,11 & ns \\
\hline Cinzas (\%) & 2,19 & 1,88 & 2,42 & 2,02 & 1,94 & 17,87 & ns \\
\hline Gordura (\%) & 15,45 & 14,86 & 14,38 & 12,03 & 13,26 & 15,68 & ns \\
\hline Proteína (\%) & 15,89 & 16,78 & 17,79 & 18,08 & 17,49 & 7,85 & ns \\
\hline CRP (\%) & 1,82 & 1,75 & 1,88 & 1,78 & 1,61 & 13,67 & ns \\
\hline DPC (g) & 38,49 & 38,51 & 38,26 & 35,67 & 30,02 & 23,52 & ns \\
\hline \multirow[t]{2}{*}{$\underline{\mathrm{DGC}}(\mathrm{g})$} & 58,02 & 51,84 & 45,74 & 33,92 & 36,84 & 15,66 & Linear $^{(2)}$ \\
\hline & \multicolumn{7}{|c|}{ Filé } \\
\hline Umidade (\%) & 72,86 & 72,96 & 73,58 & 74,89 & 74,75 & 2,57 & ns \\
\hline Cinzas (\%) & 1,03 & 1,12 & 1,11 & 1,56 & 1,06 & 30,72 & ns \\
\hline Gordura (\%) & 6,70 & 6,88 & 6,16 & 5,18 & 5,40 & 20,13 & ns \\
\hline Proteína (\%) & 18,68 & 19,00 & 19,09 & 19,28 & 19,28 & 3,68 & ns \\
\hline $\mathrm{DPF}(\mathrm{g})$ & 46,04 & 41,90 & 37,31 & 34,13 & 30,31 & 27,30 & Linear $^{(3)}$ \\
\hline DGF (g) & 24,06 & 23,41 & 18,74 & 13,50 & 13,43 & 9,98 & Linear $^{(4)}$ \\
\hline
\end{tabular}

${ }^{(1)}$ Substituição (\%) da farinha de carne suína pela mistura de farelo de soja + farelo de canola. ${ }^{(2)} \mathrm{y}=57,37-0,24 \mathrm{x}, \mathrm{R}^{2}=0,46 .{ }^{(3)} \mathrm{y}=44,21-0,14 \mathrm{x}, \mathrm{R}^{2}=0,71$. ${ }^{(4)} y=25,37-0,13 x, R^{2}=0,47$. CRP, coeficiente de retenção protéica; DPC, deposição de proteína corporal; DGC, deposição de gordura corporal; DPF, deposição de proteína no filé; DGF, deposição de gordura no filé. " ${ }^{\text {, }}$ Não significativo. para proteína e gordura no peixe inteiro, assim como foi verificado neste estudo.

Outro ponto importante a ser levantado diz respeito à relação dos demais nutrientes da dieta com a eficiência de utilização da proteína. Na carpa-húngara, a digestibilidade de óleos de origem vegetal é menor do que a de óleos de origem animal (Degani et al., 1997). Viola et al. (1982) relatam que a substituição de $40 \%$ da farinha de peixe da dieta por farelo de soja exigiu a suplementação de metionina e $5 \%$ de óleo para manter o mesmo índice de crescimento e utilização de energia e proteína pela carpa-húngara, comparando-se à dieta controle, que continha farinha de peixe como fonte proteica. No mesmo trabalho, ao se substituir totalmente a farinha de peixe por farelo de soja, foi necessária a suplementação com metionina para atender à exigência da espécie com $0,5 \%$ de lisina e $10 \%$ de óleo, para manter a taxa de eficiência proteica e o crescimento semelhante ao tratamento controle.

No presente trabalho, o teor de extrato etéreo oscilou entre os tratamentos. Os teores de gordura das dietas nos tratamentos $0,25,50,75$ e 100 foram $16,48,13,64,11,52,8,65$ e $8,55 \%$, respectivamente (Tabela 1). Os maiores níveis de gordura das dietas sem farelos vegetais foram decorrentes da alta concentração de gordura proveniente da farinha de carne. Além do crescimento, a gordura das dietas pode também ter exercido influência sobre a quantidade de gordura depositada. Na carpa-comum, Nandeesha et al. (2002) afirmam que o maior teor de gordura em alevinos

Tabela 3. Índices de carcaça e parâmetros sanguíneos de juvenis de carpa húngara (Cyprinus carpio).

\begin{tabular}{|c|c|c|c|c|c|c|c|c|}
\hline \multirow[t]{2}{*}{ Variáveis } & \multirow[t]{2}{*}{ Inicial } & \multicolumn{5}{|c|}{ Tratamentos $^{(1)}$} & \multirow[t]{2}{*}{$\mathrm{CV}(\%)$} & \multirow[t]{2}{*}{ Efeito } \\
\hline & & 0 & 25 & 50 & 75 & 100 & & \\
\hline $\mathrm{RC}(\%)$ & 86,34 & 85,68 & 85,03 & 87,53 & 86,41 & 87,46 & 3,36 & ns \\
\hline $\mathrm{RF}(\%)$ & 34,61 & 36,69 & 37,59 & 37,71 & 35,64 & 35,79 & 5,02 & ns \\
\hline IDS (\%) & 2,73 & 2,63 & 2,44 & 2,51 & 2,66 & 2,69 & 11,76 & ns \\
\hline IHS (\%) & 1,95 & 1,95 & 2,14 & 2,01 & 2,33 & 2,34 & 19,02 & ns \\
\hline QI & 1,70 & 1,90 & 2,05 & 1,80 & 1,79 & 1,84 & 7,57 & ns \\
\hline GV (\%) & 0,09 & 1,18 & 0,98 & 1,10 & 0,86 & 0,99 & 43,47 & ns \\
\hline Ast $\left(\mathrm{U} \mathrm{dL}^{-1}\right)$ & - & 75,83 & 65,40 & 66,40 & 66,00 & 74,40 & 22,14 & ns \\
\hline $\operatorname{Alt}\left(\mathrm{U} \mathrm{dL}^{-1}\right)$ & - & 62,00 & 59,60 & 45,50 & 55,83 & 55,20 & 18,18 & ns \\
\hline $\operatorname{Prot}\left(\mathrm{g} \mathrm{dL}^{-1}\right)$ & - & 2,52 & 2,90 & 2,65 & 2,76 & 2,68 & 9,38 & ns \\
\hline $\mathrm{TG}\left(\mathrm{mg} \mathrm{dL} \mathrm{L}^{-1}\right)$ & - & 181,04 & 207,59 & 190,03 & 180,72 & 170,32 & 21,73 & ns \\
\hline $\operatorname{Col}\left(\mathrm{mg} \mathrm{dL}^{-1}\right)$ & - & 108,54 & 120,47 & 101,46 & 84,61 & 81,36 & 18,32 & Linear $^{(2)}$ \\
\hline Glic $\left(\mathrm{g} \mathrm{dL}^{-1}\right)$ & - & 41,40 & 60,40 & 49,80 & 54,40 & 44,40 & 11,04 & ns \\
\hline
\end{tabular}

${ }^{(1)}$ Substituição (\%) da farinha de carne suína pela mistura de farelo de soja + farelo de canola. ${ }^{(2)} y=115,92-0,36 x, R^{2}$ 0,40. RC, rendimento de carcaça; RF, rendimento de filé; IHS, índice hepato-somático; IDS, índice digestivo-somático; QI, quociente intestinal; GV, gordura visceral; Ast, aspartato

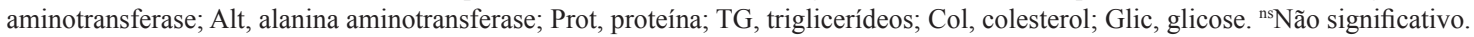


alimentados com dieta à base de farinha de peixe é relacionado à maior concentração de gordura deste ingrediente. Nenhuma diferença foi encontrada para os parâmetros rendimento de carcaça, rendimento de filé, índice hepato-somático, índice digestivo-somático, quociente intestinal e gordura visceral ao final do experimento (Tabela 3 ).

D'Souza et al. (2006), em trabalhos com dietas que utilizaram os níveis de 20 e $40 \%$ de inclusão de farelo de soja e um tratamento controle à base de farinha de peixe, estudaram a influência dessa inclusão sobre a qualidade dos filés de truta arco-íris (Oncorhynchus mykiss Walbaum, 1792). Foram encontradas diferenças quanto à cor e à análise sensorial, em que o tratamento com $40 \%$ de inclusão diferiu do controle. Também em trabalhos com truta arco-íris e dietas à base de fontes vegetais, Francesco et al. (2004) encontraram diferença para cor, tanto na análise sensorial como na avaliação instrumental. Neste estudo, os parâmetros sensoriais cor e sabor não diferiram significativamente entre os tratamentos (Tabela 4). Da mesma forma, a avaliação instrumental da cor (Cielab) não mostrou diferenças significativas.

Entre os parâmetros sanguíneos, para colesterol, foi observado efeito linear negativo da inclusão da mistura de fontes proteicas vegetais (Tabela 3). $\mathrm{Na}$ avaliação de juvenis de bacalhau do Atlântico (Gadus morhua Linnaeus, 1758), Hansen et al. (2007) observaram que os peixes alimentados com farelos vegetais apresentaram menor colesterol circulante que os alimentados com a dieta controle com farinha de peixe, resultado atribuído aos fatores antinutricionais presentes nos farelos vegetais, especialmente fibra e polissacarídeos não amiláceos.

Tabela 4. Parâmetros sensoriais e de cor do filé de carpa húngara (Cyprinus carpio) ao final do experimento.

\begin{tabular}{|c|c|c|c|c|c|c|}
\hline \multirow[t]{2}{*}{ Variáveis } & \multicolumn{5}{|c|}{ Níveis de substituição (\%) ${ }^{(1)}$} & \multirow[t]{2}{*}{ Efeito } \\
\hline & 0 & 25 & 50 & 75 & 100 & \\
\hline & \multicolumn{6}{|c|}{ Sensorial } \\
\hline Cor & 99 & 103 & 85 & 86 & 77 & ns \\
\hline \multirow[t]{2}{*}{ Sabor } & 93 & 96 & 90 & 76 & 95 & ns \\
\hline & \multicolumn{6}{|c|}{$\operatorname{Cor}^{(2)}$} \\
\hline $\mathrm{L}$ & 49,91 & 47,94 & 50,32 & 49,48 & 52,12 & ns \\
\hline A & 11,86 & 12,68 & 12,58 & 11,06 & 11,39 & ns \\
\hline $\mathrm{B}$ & 1,87 & 1,64 & 3,06 & 2,04 & 3,07 & ns \\
\hline
\end{tabular}

\$(1) Substituição da farinha de carne suína pela mistura de farelo de soja + farelo de canola. ${ }^{(2)}$ Determinação instrumental da cor: L, luminosidade; A, direção para o vermelho (+a) ou para o verde (-a); B, direção para o

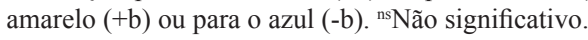

A fibra reduz a capacidade de formação de micelas no intestino, e os polissacarídeos não amiláceos se ligam aos sais biliares, de forma a impedir a absorção das gorduras, aumentar a excreção de colesterol nas fezes e reduzir o colesterol circulante (Krögdahl et al., 2005). Essas informações podem auxiliar no esclarecimento dos resultados obtidos neste experimento. Embora as dietas apresentassem teor equivalente de fibra em detergente neutro (FDN) (Tabela 1), a proporção entre fibra solúvel e insolúvel provavelmente foi alterada, uma vez que foram utilizados ingredientes diferentes para equilibrar as dietas, tais como farelo de trigo, milho, farelo de canola e farelo de soja.

A determinação dos parâmetros bioquímicos é importante para o conhecimento do metabolismo dos peixes em função das alterações da dieta, além de servirem como indicativos de estado nutricional e de saúde (Shikata \& Shimeno, 1998; Kumar et al., 2010). Mesmo não sendo influenciados pelos tratamentos, nos níveis plasmáticos de triglicerídeos, proteínas totais e glicose foram semelhantes aos observados em tratamentos controle de outros estudos (Shikata \& Shimeno, 1998; Kumar et al., 2010).

É importante salientar que a idade e o peso dos peixes, assim como o conteúdo total de lipídios na dieta, podem influenciar o aproveitamento da proteína (Degani et al., 1997). Vários estudos têm avaliado níveis e fontes de lipídios em dietas para peixes. A utilização de lipídios e de carboidratos varia de acordo com a espécie e com a fonte, e pode afetar a digestibilidade dos demais nutrientes. Dessa forma, resultados divergentes são frequentemente apresentados e compreensíveis.

Os ingredientes proteicos de origem vegetal apresentam valor nutricional elevado, o que os caracteriza como potenciais alternativas às fontes de origem animal. Contudo, eles podem possuir antinutrientes ou compostos tóxicos para os peixes. Nesse sentido, a obtenção de informações detalhadas a respeito da composição química dessas fontes é de extrema importância para maximizar a utilização desses ingredientes em dietas para peixes.

\section{Conclusões}

1. A mistura de farelo de soja e farelo de canola, em substituição à farinha de carne suína, reduz o crescimento e altera parâmetros bioquímicos de juvenis de carpa- húngara. 
2. A substituição da farinha de carne suína pela mistura de farelo de soja e farelo de canola não causa interferência nos parâmetros de carcaça e nas características sensoriais da carne de carpa-húngara.

\section{Referências}

ALLAN, G.L.; ROWLAND, S.J. Performance and sensory evaluation of silver perch (Bidyanus bidyanus Mitchell) fed soybean or meat meal-based diets in earthen ponds. Aquaculture Research, v.36, p.1322-1332, 2005.

BLIGH, E.G.; DYER, W.J. A rapid method of total lipid extraction and purification. Canadian Journal of Biochemistry and Physiology, v.37, p.911-917, 1959.

BUREAU, D.P.; KAU SHIK, S.J.; CHO, C.Y. Bioenergetics. In: HALVER, J.E.; HARDY, R.W. Fish nutrition. San Diego: Academic, 2002. p.1-59.

CAMPESTRINI, E. Farinha de carne e ossos. Revista Eletrônica Nutritime, v.2, p.221-234, 2005.

D'SOUZA, N.; SKONBERG, D.I.; STONE, D.A.J.; BROWN, P.B. Effect of soybean meal-based diets on the product quality of rainbow trout fillets. Journal of Food Science, v.71, p.337-342, 2006.

DEGANI, G.; VIOLA, S.; YEHUDA, Y. Apparent digestibility coefficient of protein sources for carp, Cyprinus carpio L. Aquaculture Research, v.28, p.23-28, 1997.

DUTCOSKY, S.D. Análise sensorial de alimentos. 2.ed rev. e ampl. Curitiba: Champagnat, 2007. 239p.

EL-SAYED, A.F.M. Alternative dietary protein sources for farmed tilapia, Oreochromis spp. Aquaculture, v.179, p.149-168, 1999.

FRANCESCO, M. de; PARISI, G.; MEDALE, F.; LUPI, P.; KAUSHIK, S.J.; POLI, B.M. Effect of long-term feeding with a plant protein mixture based diet on growth and body/fillet quality traits of large rainbow trout (Oncorhynchus mykiss). Aquaculture, v.236, p.413-429, 2004.

GATLIN III, D.M.; BARROWS, F.T.; BROWN, P.; DABROWSKI, K.; GAYLORD, T.G.; HARDY, R.W.; HERMAN, E.; HU, G.; KROGDAHL, A.; NELSON, R. ; OVERTURF, K.; RUST, M.; SEALEY, W.; SKONBERG, D.; SOUZA, E.J.; STONE, D.; WILSON, R.; WURTELE, E. Expanding the utilization of sustainable plant products in aquafeeds: a review. Aquaculture Research, v.38, p.551-579, 2007.

GODA, A.M.; EL-HAROUN, E.R.; CHOWDHURY, M.A.K. Effect of totally or partially replacing fish meal by alternative protein sources on growth of African catfish Clarias gariepinus (Burchell, 1822) reared in concrete tanks. Aquaculture Research, v.38, p.279-287, 2007.

HANSEN, A.-C; KARLSEN, Ø.; ROSENLUND, G.; RIMBACH, M.; HEMRE, G.-I. Dietary plant protein utilization in Atlantic cod, Gadus morhua L. Aquaculture Nutrition, v.13, p.200-215, 2007.

HASAN, M.R.; MACINTOSH, D.J.; JAUNCEY, K. Evaluation of some plant ingredients as dietary protein sources for common carp (Cyprinus carpio L.) fry. Aquaculture, v.151, p.55-70, 1997.
JAHAN, P.; WATANABE, T.; KIRON, V.; SATOH, S. Balancing protein ingredients in carp feeds to limit discharge of phosphorus and nitrogen into water bodies. Fisheries Science, v.69, p.226-233, 2003a.

JAHAN, P.; WATANABE, T.; KIRON, V.; SATOH, S. Improved carp diets based on plant protein sources reduce environmental phosphorus loading. Fisheries Science, v.69, p.219-225, 2003b.

KIM, M.K.; ÖZKÖK, E.; HAN, I.K. Effect of soybean meal and full-fat soybean for fish meal protein replacement on the growth performance of carp grower. Korean Journal of Animal Nutrition and Feedstuffs, v.21, p.503-510, 1997.

KRÖGDAHL, A.; HEMRE, C.I.; MOMMSEN, T.P. Carbohydrates in fish nutrition: digestion and absorption in postlarval stages. Aquaculture Nutrition, v.11, p.103-122, 2005.

KUMAR, V.; MAKKAR, H.P.S.; AMSELGRUBER, W.; BECKER, K. Physiological, haematological and histopathological responses in common carp (Cyprinus carpio L.) fingerlings fed with differently detoxified Jatropha curcas kernel meal. Food and Chemical Toxicology, v.48, p.2063-2072, 2010.

LUO, L.; XUE, M.; WU, X.; CAI, X.; CAO, H.; LIANG, Y. Partial or total replacement of fishmeal by solvent-extracted cottonseed meal in diets of juvenile rainbow trout (Oncorhynchus mykiss). Aquaculture Nutrition, v.12, p.418-424, 2006.

MEIlgaARD, M.; CIVIlle, G.V.; CARR, B.T. Sensory evaluation techniques. 2.ed. Boca Raton: CRCP, 1991. 354p.

MÜLLER, M.D.; CARVALHO, G.R.; FERNANDES, E.N. Impacto do aumento da demanda de biodiesel no custo da alimentação animal. In: CONGRESSO DA REDE BRASILEIRA DE TECNOLOGIA DE BIODIESEL, 2., 2007, Brasília. Anais. Brasília: ABIPTI, 2007. Disponível em: <http://www.biodiesel. gov.br/docs/congresso2007/desenvolvimento/15.pdf>. Acesso em: 15 dez. 2008.

NANDEESHA, M.C.; GANGADHARA, B.; MANISSERY, J.K. Further studies on the use of mixed feeding schedules with plant- and animal-based diets for common carp Cyprinus carpio (Linnaeus). Aquaculture Research, v.33, p.1157-1162, 2002.

NATIONAL RESEARCH COUNCIL. Nutrient requirements of fish. Washington: National Academy, 1993. 115p.

NAYLOR, R.L.; GOLDBURG, R.J.; PRIMAVERA, J.H.; KAUTSKY, N.; BEVERIDGE, M.C.M.; CLAY, J.; FOLKE, C.; LUBCHENCO, J.; MOONEY, H.; TROELL, M. Effect of aquaculture on world fish supplies. Nature, v.405, p.1017-1024, 2000.

PEREIRA-DA-SILVA, E.M.; PEZZATO, L.E. Respostas da tilápia do Nilo (Oreochromis niloticus) à atratividade e palatabilidade de ingredientes utilizados na alimentação de peixes. Revista Brasileira de Zootecnia, v.29, p.1273-1280, 2000.

POLI, C.R.; ARANA, L.V. Qualidade da água em aqüicultura. In: POLI, C.R.; POLLI, A.T.B.; ANDREATTA, E.R.; BELTRAME, E. Aqüicultura: experiências brasileiras. Florianópolis: Multitarefa, 2004. p.45-72.

SHIKATA, T.; SHIMENO, S. Effect of quality of dietary protein on body composition and hepatopancreatic enzyme activities in 
carp. Bulletin of Ishikawa Prefecture Fish Research Centre, v.1, p.31-35, 1998.

SILVA, L.B. da; BARCELLOS, L.J.G.; MEZZALIRA-QUEVEDO, R.; SOUZA, S.M.G. de; KREUTZ, L.C.; RITTER, F.; FINCO, J.A.; BEDIN, A.C. Alternative species for traditional carp polyculture in southern South America: initial growing period. Aquaculture, v.255, p.417-428, 2006.

SOUZA, S.R. de; HAYASHI, C.; GALDIOLI, E.M.; SOARES, C.M.; MEURER, F. Diferentes fontes protéicas de origem vegetal para tilápia do Nilo (Oreochromis niloticus L.) durante a reversão sexual. Acta Scientiarum. Animal Sciences, v.26, p.21-28, 2004.
VIEGAS, E.M.M.; CARNEIRO, D.J.; URBINATI, E.C.; MALHEIROS, E.B. Farelo de canola em dietas para o pacu Piaractus mesopotamicus (Holmberg 1987): efeitos sobre o crescimento e a composição corporal. Arquivo Brasileiro de Medicina Veterinária e Zootecnia, v.60, p.1502-1510, 2008.

VIOLA, S.; MOKADY, S.; RAPPAPORT, U.; ARIELI, Y. Partial and complete replacement of fishmeal by soybean meal in feeds for intensive culture of carp. Aquaculture, v.26, p.223-236, 1982.

ZANIBONI FILHO, E. Piscicultura das espécies exóticas de água doce. In: POLI, C.R.; POLLI, A.T.B.; ANDREATTA, E.R.; BELTRAME, E. Aqüicultura: experiências brasileiras. Florianópolis: Multitarefa, 2004. p.309-336.

Recebido em 21 de abril de 2010 e aprovado em 29 de setembro de 2010 